\title{
In-plane shear behaviour of traditional timber walls
}

\author{
Graça Vasconcelos ${ }^{1}$, Elisa Poletti1, Eunice Salavessa ${ }^{2}$, Abílio A.M Jesus ${ }^{3}$, \\ Paulo B. Lourenço', Preecha Pilaon ${ }^{4}$
}

\begin{abstract}
The reconstruction of Lisbon Downtown after the 1755 earthquake was based on a novel constructive system based on masonry buildings with an internal three-dimensional timber-framed structure named "gaiola pombalina". This internal structure aimed at improving the global stability of masonry buildings, enhancing their capacity to dissipate energy under seismic loadings. This paper aims at getting experimental insight on the mechanical behaviour of such timber-framed walls subjected to in-plane loading, as only scarce information is available in literature, in order to assess their effective performance to seismic actions. To do this, the experimental results of cyclic tests carried out on traditional timber-framed walls with distinct typologies will be analyzed, in order to evaluate the failure modes, lateral resistance and energy dissipation; moreover, a hysteretic model will be derived for traditional timber-framed walls. Additionally, the possibility of strengthening the traditional connections of the walls by means of GFRP is also addressed.
\end{abstract}

Keywords timber-framed wall, cyclic tests, shear resistance, dissipation of energy, ultimate deformation, hysteresis model

\section{INTRODUCTION}

Half-timbered buildings are well known as one of the most efficient seismic resistant structures in the world, but their popularity is not only due to their seismic performance, but also to their low cost and the strength they offer. A great research effort has been made on the historic materials and structures in order to gain a better understanding on their mechanical behaviour and to propose remedial and strengthening methods for world heritage structures, but little has been done for traditional timber frame walls. An important issue is to study these kinds of structures under cyclic and dynamic loads to better understand their behaviour when subjected to horizontal loads, as they represent an important cultural heritage for many countries and they have to be preserved. Moreover, the hysteretic laws of half-timbered walls will be studied in order to gain information on their dissipative behaviour.

\footnotetext{
${ }^{1}$ ISISE, Department of Civil Engineer, University of Minho, Portugal (graca@ civil.uminho.pt) ${ }^{2}$ Engineering Department - ECT, University of Trás-os-Montes e Alto Douro, Portugal ${ }^{3}$ IDMEC/LAETA/ Engineering Department - ECT, University of Trás-os-Montes e Alto Douro, Portugal

${ }^{4}$ Master Student, Master in Structural Analysis in Historical Constructions
} 


\section{TRADITIONAL HALF-TIMBERED STRUCTURES}

\subsection{Traditional half-timbered walls}

The origin of half-timbered structures probably goes back to the Roman Empire, as in archaeological sites half-timber houses were found and were referred to as Opus Craticium by Vitruvius (Langenbach 2009). These constructions later spread not only throughout Europe, such as Portugal (edifícios pombalinos), Italy (casa baraccata), Germany (fachwerk), Greece, France (colombage), Scandinavia, United Kingdom (half-timber), Spain (entramados) etc., but also in India (dhaji-dewari) and Turkey (himis) (Cóias 2007; Langenbach 2009). In each country different geometries were used, but the common idea is that the timber frame can resist to tension, contrary to masonry, thus providing a better resistance to horizontal loads and moreover providing a sort of confinement to the masonry structure.

In Portugal, typical half-timbered structures are the 'Pombalino' buildings, which are old masonry buildings developed after the 1755 Lisbon earthquake which destroyed Lisbon Downtown. The new buildings took their name from the prime minister of the time, the Marquis of Pombal, who encouraged the reconstruction of the city. A Pombalino building is characterized by external masonry walls and an internal timber structure, named "gaiola" (cage), see Figure 1, which is a three-dimensional braced timber structure. The "gaiola" consists of horizontal and vertical elements and diagonal bracing members. These timber frame walls are filled with rubble brick masonry.

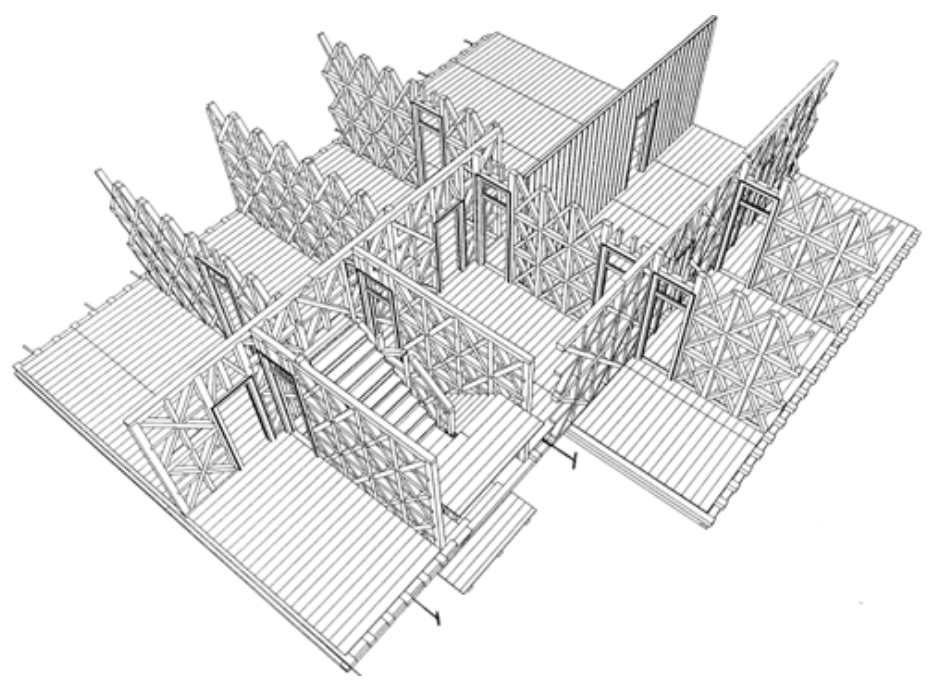

Figure 1 - The Gaiola system in the Pombalino buildings (Cóias 2007).

The internal walls of the "gaiola" (paredes em frontal) may have different geometries in terms of cell dimensions and number of elements, as it depended greatly on the available space and the manufacturer's customs (Figure 2). Discordances are met also in the sectional dimensions of the elements themselves: the diagonal members are usually smaller $(10 \times 10 \mathrm{~cm})$, whilst the vertical studs and horizontal members are bigger (usually $12 \times 10$ and $12 \times 15 \mathrm{~cm}$ or $15 \times 13$ and $10 \times 13$ respectively). The thickness of the walls can vary from 15 to 20cm (Mascarenhas 2004; França 1983).

The timber-framed walls, as the inner leaf of the masonry walls, are adequately connected to the masonry piers of the main façade. Generally the vertical columns are connected to the timber elements of the floors by means of iron elements. The timber elements of the "gaiola" are usually notched together or connected by nails or iron ties, according to existing construction techniques. 

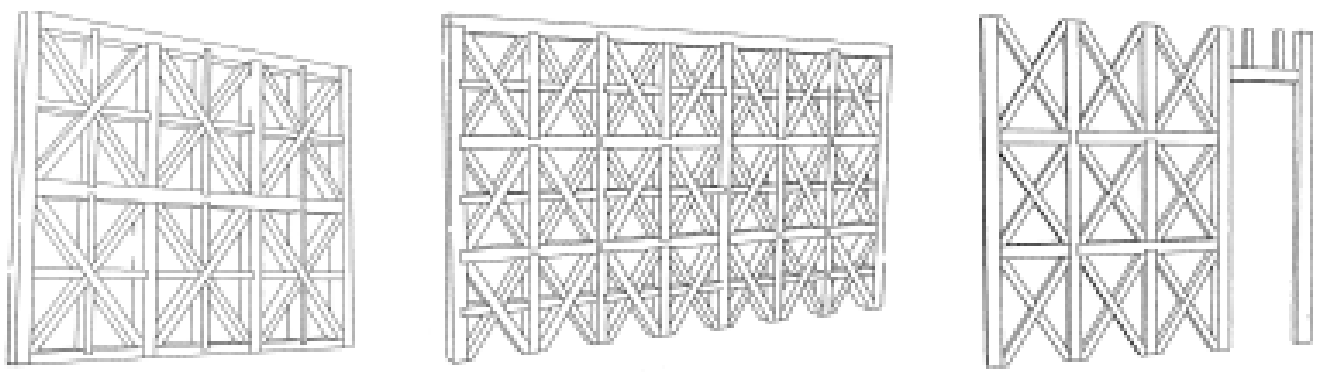

Figure 2 - Different wall geometries in Pombalino buildings (Cóias 2007).

It is common to find similar structures also in the north of the country, even though the seismic hazard is lower. This is mainly due to the fact that this kind of construction is also economical, as it uses less masonry and wood is largely available in Portugal.

\subsection{Behaviour under cyclic loading}

The experimental and numerical research available in literature on timber shear walls relates mainly to timber sheathing panels with mechanical connections. With respect to traditional timber frame walls only very scarce information is available from both an experimental and a numerical point of view. However, it is considered that the experimental tests performed on modern timber walls with wood sheathing panels can give some clues as to how an experimental procedure should be carried out.

In relation to Pombalino half-timbered walls, almost no experimental information is available until now. An experimental testing campaign was found in literature concerning ancient timber frame walls tested in the scope of a rehabilitation program of ancient masonry buildings (Santos 1997). A real wall specimen was extracted from an existing building which was going to be demolished and tested cyclically (Cóias e Silva 2002). The hysteresis loops shown in Figure 3 are quite wide, indicating a good energy dissipation capacity of the structure. In fact, the structure, even though subjected to higher loads than those generally met in an earthquake, was able to maintain its integrity with little damage. The envelope curve is actually continuously increasing, indicating that the ultimate capacity of the structure had not been reached (Langenbach 2007).
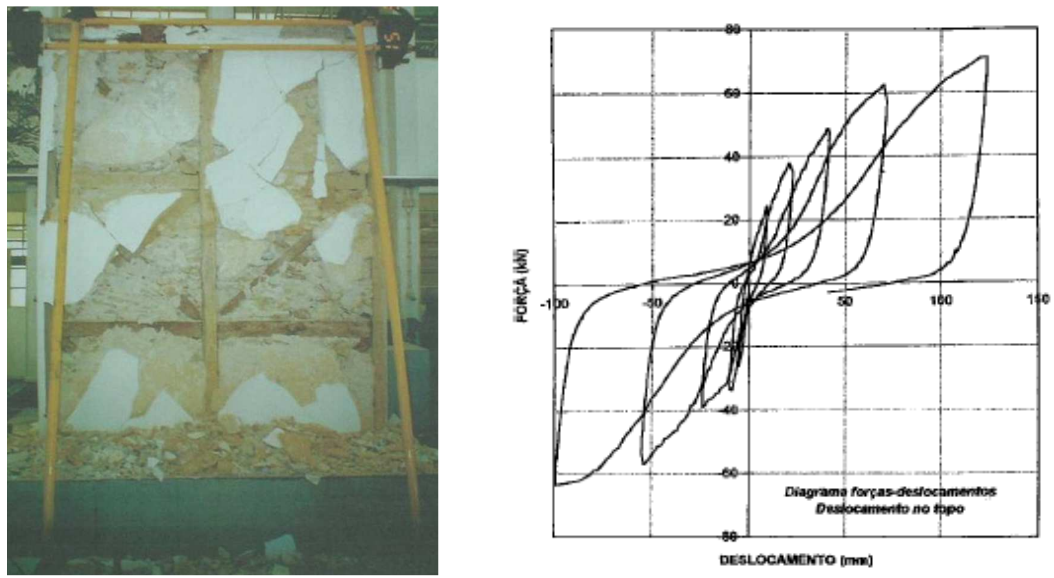

Figure 3 - Real wall specimen after test and hysteresis curves obtained (Langenbach 2007).

Nowadays, timber shear walls are common in the USA, Canada and in Northern Europe, where there is a great availability of wood. In the last years studies concerning timber shear walls have focused mainly on the comparison among static, cyclic and dynamic responses of this kind of walls in order to better understand their behaviour under lateral loading.

In general, a timber shear wall consists of double end studs, a single or double top plate, a single bottom plate and interior studs. The sheathing material is usually constituted of plywood or OSB (Oriented Strand Board) panels. Many of the experimental tests have been performed on 
$2.44 \times 2.44 \mathrm{~m}(8 \times 8 \mathrm{ft})$ shear walls, a typical wall dimension in a residential house in the US and Canada (Faulz and Filiatrault 2001).

The studies show that the force-deformation response of a timber frame shear wall under cyclic or reverse loading is highly nonlinear even at low force levels (Pang et al. 2007). Furthermore, timber shear walls are capable of dissipating a large amount of energy through the behaviour of individual fasteners (Dinehart and Shenton III 1998). The behaviour is also influenced by vertical load, as it increases the lateral stiffness and the energy dissipation, nail spacing and hold-down anchors (Johnston et al. 2006). It is commonly accepted that the load-deformation behaviour and energy absorbing characteristics of shear walls are decided mainly by the joint characteristics. Therefore connector behaviour under both monotonic and cyclic loading conditions related to shear walls has been investigated extensively by many researchers (Lam et al. 1997).

\subsection{Hysteretic modelling of timber shear walls}

A hysteretic model is a mathematical model that describes the force-displacement response of a structure under cyclic loading over a time period. It is used in the analytical modelling of an inelastic structure in such a way that nonlinear damping mechanisms can be modelled.

Various hysteretic models are available in literature. One of the basic models which has then been developed by various authors is the Takeda model (Takeda et al. 1970). Two models are available, namely the Takeda 'Thin' and Takeda 'Fat'. The first is suitable for modelling building frames, while the latter is suitable for modelling concrete walls and columns (Priestley et al. 2007).It is an elasto-plastic hysteretic model which simulates the actual behavioural stage of a structure or an element by a set of linear segments forming a polygonal shaped model. In order to take account of the pinching effect, a model was proposed by Ibara et al.(2005). The model is similar to the Takeda one but the reloading branch is composed of two branches aiming at modelling the pinching behaviour. Moreover, he proposed an energy-based approach to calculate the cyclic deterioration.

\section{BRIEF DESCRIPTION OF TESTS LAYOUT}

\subsection{Test specimens}

Three wall typologies were considered: unreinforced walls (UTW), reinforced walls with Fiber-Reinforced Plastic (RTW) and infill walls (ITW). Nine wall specimens, three identical samples for each typology, were made and subjected to cyclic loading in vertical and horizontal direction. All walls were $80 \times 90 \mathrm{~cm}$. For each wall typology, each specimen was subjected to 3 different vertical load levels to investigate the effect of the pre-compression level on the seismic performance of timber shear walls.

For all wall typologies, the frame's main skeleton consists of three continuous posts and two continuous horizontal members at the top and the bottom of the frame, having a cross-section of $5 \times 7 \mathrm{~cm}$ (see Figure 4).

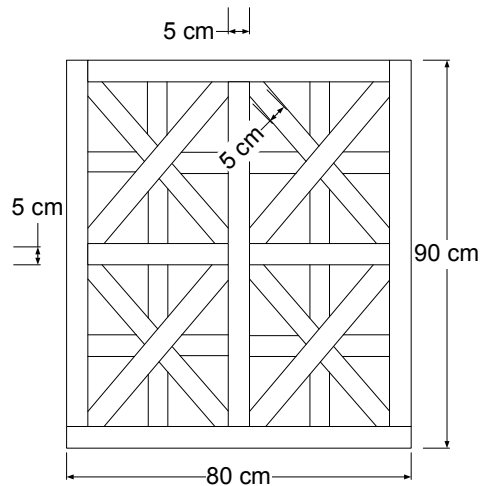

(a)

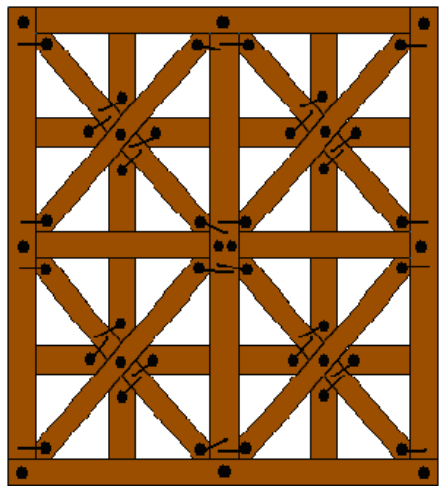

(b)

Figure 4 - Configuration of the specimen: (a) dimensions; (b) location of the nails driven into the wood. 
UTW specimens consisted only of the timber frame (see Figure 5a). In RTW specimens sheets glued with epoxy resin were applied in the central connections of the walls, namely in correspondence of St. Andrew's crosses and in the central connection (see Figure 5b). ITW specimens consisted of the timber frame filled with bricks (see Figure 5c). The brick was shaped into triangular prism about $1 \mathrm{~cm}$ less in size than that of an empty triangular space and with a thickness of $6 \mathrm{~cm}$ so that it accommodated the presence of a $1 \mathrm{~cm}$ mortar layer which supported the bricks at the back side of the wall. The mortar was composed of cement, sand, hydraulic lime (with the quantity of 2:6:3 by weight, respectively) and water.

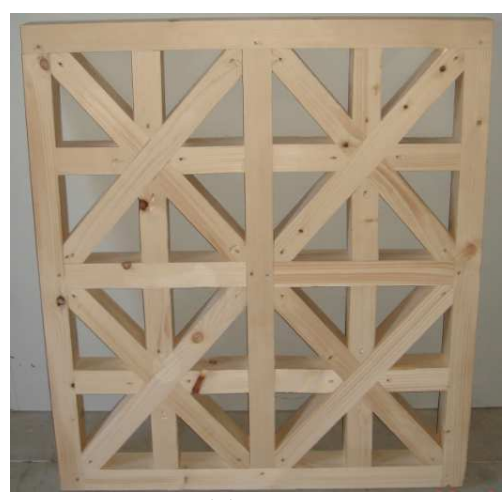

(a)

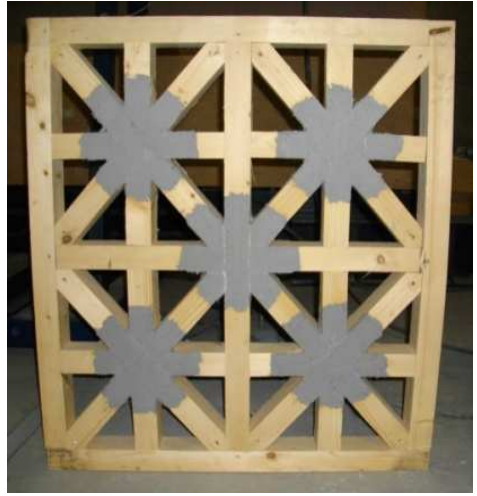

(b)

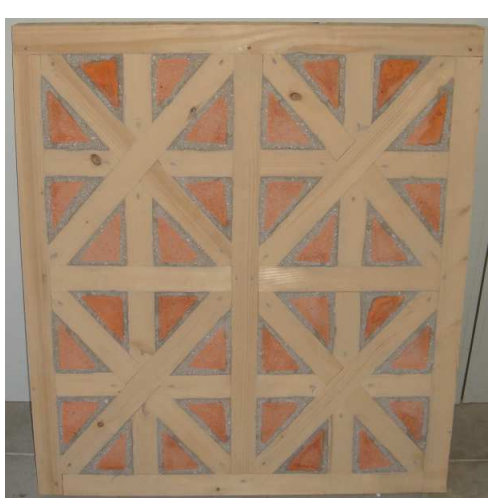

(c)

Figure 5 - Wall specimens: (a) UTW; (b) RTW; (c) ITW.

All nine specimens were built in Spruce Pine. The material was physically and mechanically characterized, considering its relative humidity (HR), density $(\rho)$, compressive strength and modulus of elasticity (E).

The average HR on 10 prismatic specimens was $8.6 \%$ [1.74], a low value considering that usually the minimum value of HR for wood to be used is of $12 \%$. It can be concluded that this wood is very dry. On 10 prismatic specimens, the average density was $420 \mathrm{~kg} / \mathrm{m}^{3}$ [4.14], the average modulus of elasticity 13291.1MPa [13.1] and the average compressive strength 45.5MPa [5.1].

\subsection{Test setup}

Cyclic tests were performed on the three above described specimens. For each of the three specimens of each type, a different vertical pre-compression was applied. The walls were restrained at the bottom using steel angles that fixed the bottom of the wall to a steel beam which was connected to the floor; the load was applied through a vertical actuator with a maximum capacity of $250 \mathrm{kN}$ to a steel beam on top of the wall through a set of steel rollers, which were placed to allow relative displacement of the wall with regard to the vertical actuator, to better distribute the load. Two actuators were used: one applied the vertical load, as mentioned above; the other one applied the horizontal load and it was connected to a reaction wall and to the top beam, which was appropriately strengthened with internal ribs, via a two-dimensional hinge that allowed vertical displacement and rotation. The horizontal load was transmitted through the wall by means of the top steel beam. The data was gathered by means of thirteen LVDTs placed in strategic positions on the wall, in order to capture the behaviour of the walls. The test setup was similar to that used previously in University of Minho for cyclic tests on masonry walls (Vasconcelos and Lourenço 2009).

After a preliminary vertical test was carried out on the walls, which will not be discussed here, horizontal cyclic tests were performed. A typical cyclic displacement schedule applied to the specimens is showed in Figure 6. The horizontal displacement load was applied increasing the displacement at each cycle. Note that the cycles were not repeated as it is suggested by current standards, thus not allowing to evaluate the re-arrangement in the structure given by the repetition of the cycle. Different vertical loads were applied to the different walls. For the three unreinforced timber walls (UTM) the pre-compression applied on top of the wall was of 25,43 and $70 \mathrm{kN}$, for the reinforced timber frame walls (RTM) of 43,70 and $100 \mathrm{kN}$ and for the infill half-timbered walls (ITM) of 100,70 and $80 \mathrm{kN}$. 


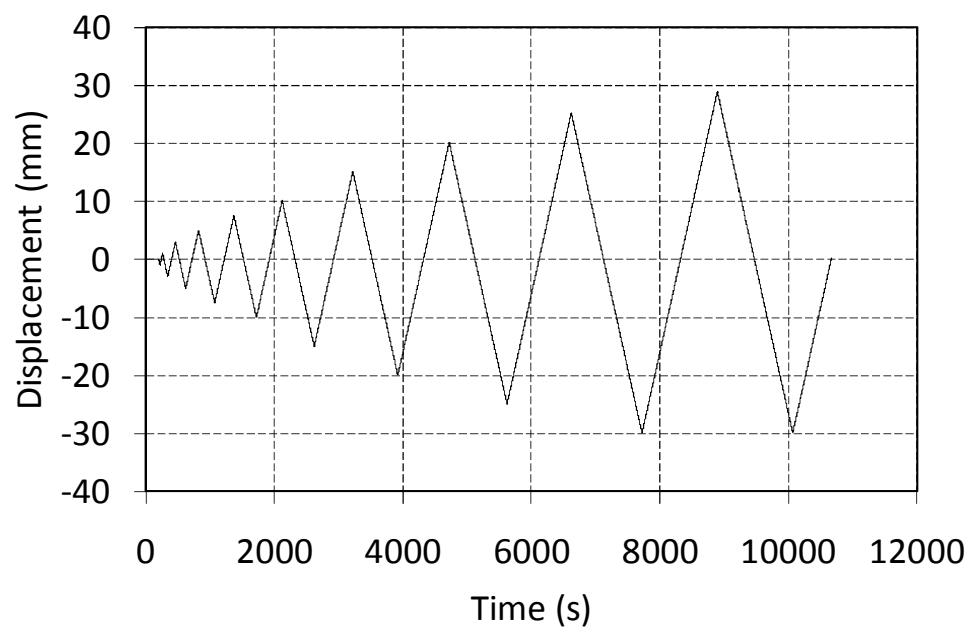

Figure 6 - Typical cyclic displacement schedule.

\section{ANALYSIS OF TEST RESULTS}

In the seismic design of new timber structures or the rehabilitation of existing structures, including historic timber frame walls, the study of the seismic response is essential. Since the seismic response of timber structures is very complex and time dependant, a better understating of the hysteretic factors that govern the problem is important for a safe and economical seismic design. These factors, such as ductility, energy dissipation, overall cyclic stiffness, equivalent viscous damping ratio, lateral drift, etc., characterize the behaviour of timber shear walls and are helpful in evaluating the performance of a structure under cyclic loading.

\subsection{Ductility}

The envelope curves were derived for the tested walls in order to evaluate their ductility. Displacement ductility is defined as the ratio between the maximum displacement and the yield displacement. Ductility is an important factor for structures in seismic regions, as it gives an estimation of how much a structure can deform nonlinearly even when near the ultimate resistance without a significant loss of strength or stiffness. It is observed that the envelope curves from all walls do not have distinct yield points (see Figure 7). Moreover, it is not always possible to capture the descending branch of the curve, meaning that the real resistance of the wall has not been reached. In general, all walls exhibit almost constant strength after they pass the yield point as the displacement increases. This reflects the elasto-plastic behaviour of the walls. The bilinear idealization is a perfectly elasto-plastic representation of the actual response of the wall specimen and it is used to evaluate the ductility of the walls. The values of ductility varied in a wide range, from 5.48 to 14.24 (positive direction) and 5.52 to 19.98 (negative direction), and show no obvious trend since the data are scattered and most of the walls were not tested until failure (see Table 1). However, it appears that ductility decreases with the increase in vertical load up to the level which can induce shear failure. For example, for ITW1 $(\mathrm{N}=100 \mathrm{kN})$ the value of ductility in the positive direction is 5.48 , for ITW3 $(\mathrm{N}=80 \mathrm{kN}) 12.54$ and for ITW2 $(\mathrm{N}=70 \mathrm{kN}) 13.24$ (Pilaon 2010). 


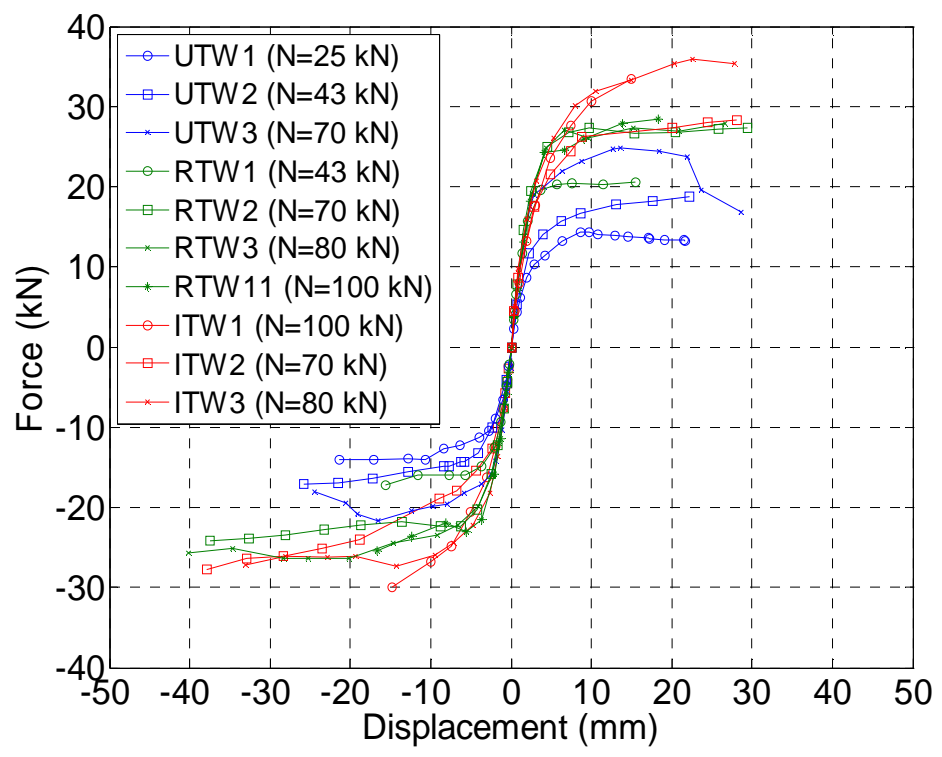

Figure 7 - Envelope curves of wall specimens.

Comparing the results with those of other authors (Toothman 2003, Heine 1997) it appears that traditional shear walls possess relatively higher ductility than modern timber shear walls even when calculated at a lower level of the anticipated failure displacement.

Table 1 - Ductility values for tested wall specimens.

\begin{tabular}{ccccccccccc}
\hline WALL & UTW1 & UTW2 & UTW3 & RTW1 & RTW2 & RTW3 & UTW1 & UTW2 & UTW3 \\
\hline $\boldsymbol{\mu}$ (positive direction) & 11.6 & 11.89 & 14.17 & 9.49 & 14.24 & 12.12 & 5.48 & 13.24 & 12.54 \\
$\boldsymbol{\mu}$ (negative direction) & 12.99 & 13.59 & 15.28 & 9.71 & 19.02 & 19.98 & 5.52 & 17.95 & 16.48 \\
\hline
\end{tabular}

\subsection{Energy dissipation}

The energy dissipated by the wall, $\mathrm{E}_{\mathrm{D}}$, can be computed at each load cycle by calculating the area enclosed by the loop in the load-displacement diagram. It represents the amount of energy dissipated during the cyclic loading which occurs through friction between joints, yielding of nails and non-recoverable deformation (residual deformation) in the wall panel. Since the walls are tested with different displacement amplitudes and loading schemes, the comparison of the energy dissipation with the number of load cycles may not be relevant. To properly compare the energy dissipation for all wall specimens, the plot of the energy dissipation against lateral drift is required.

The amount of energy dissipated in the specimen is not significantly different from one another for lateral drifts less than $0.5 \%$ for UTW and RTW, and $1 \%$ for ITW, respectively (Figure 8a). In these areas the walls were still in the elastic field and developed a low damage. After these drifts, the energy dissipation exponentially increases with the increase of lateral drift. The maximum energy dissipation occurs in RTW3, which corresponds to the vertical load of $80 \mathrm{kN}$, so the reinforcement seems to improve this aspect. The lowest amount of energy dissipated occurs in UTW1, which has the lowest vertical load $(25 \mathrm{kN})$. In general, the UTW walls dissipate less energy, even if in a minimum quantity, pointing out the contribution given by the infill in the other cases. 


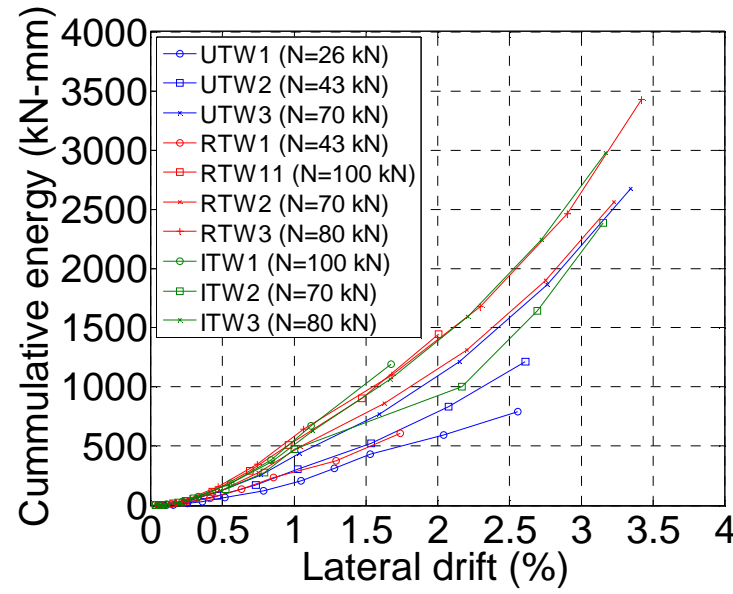

(a)

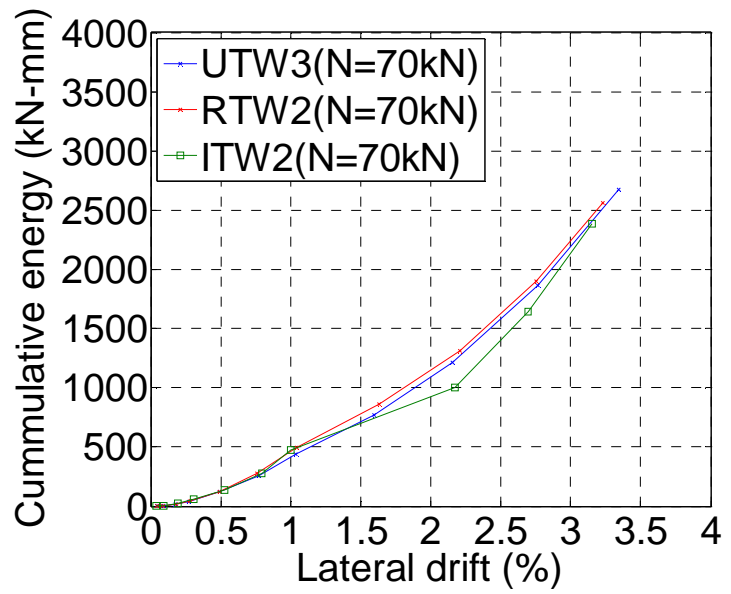

(b)

Figure 8 - Cumulative energy dissipated by wall specimens vs. lateral drift.

It is not possible to evaluate an ulterior increase of energy dissipation after the peak load, as the information is available only for a few specimens. Nevertheless, considering for example UTW3, it appears that after the peak the curve becomes slightly steeper. Moreover, the amount of dissipated energy increases with the vertical load, but for the same vertical load the amount of dissipated energy does not depend on the typology of the wall (see Figure $8 b$ ). With higher vertical loads the damage to the connections is more significant as there is a greater shear effect and a trend to compact (Pilaon 2010). Similar results are met also in cyclic tests performed on masonry walls (Vasconcelos and Lourenço 2009).

\subsection{Overall cyclic stiffness}

The overall cyclic stiffness was calculated for each cycle finding the slope of a line connecting the point of maximum displacement and the corresponding response force in both positive and negative direction. By tracking the change in the overall cyclic stiffness, stiffness degradation of the wall subjected to cyclic loading is reported. Stiffness degradation is a result of the damage cumulated in the timber connections. The energy is dissipated through nail behaviour, internal friction and formation of cracks in the wood. The nails could be torn into the wood grain forming a hole surrounding it or the nails can be pulled out of the frame during the progressive reversal of the load cycles. Thus, the next cycle has to be displaced that amount of slip before the wall can fully resist the applied load. This results in a reduction in the stiffness of the wall. The overall cyclic stiffness is plotted against lateral drift in Figure 9a.

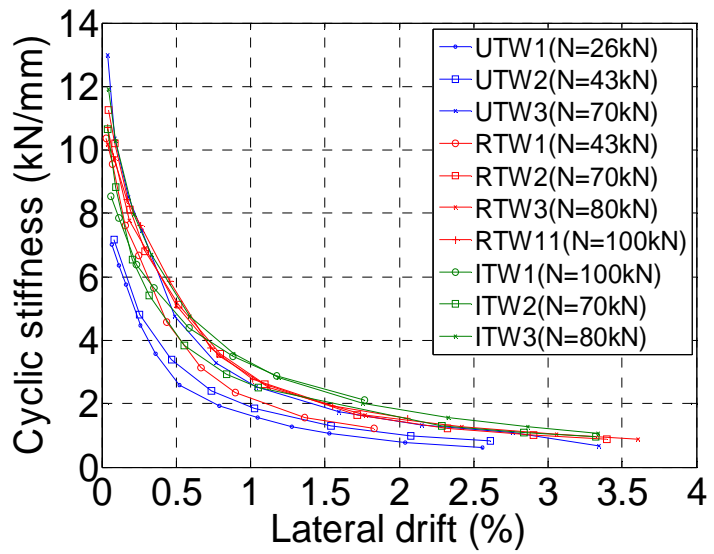

(a)

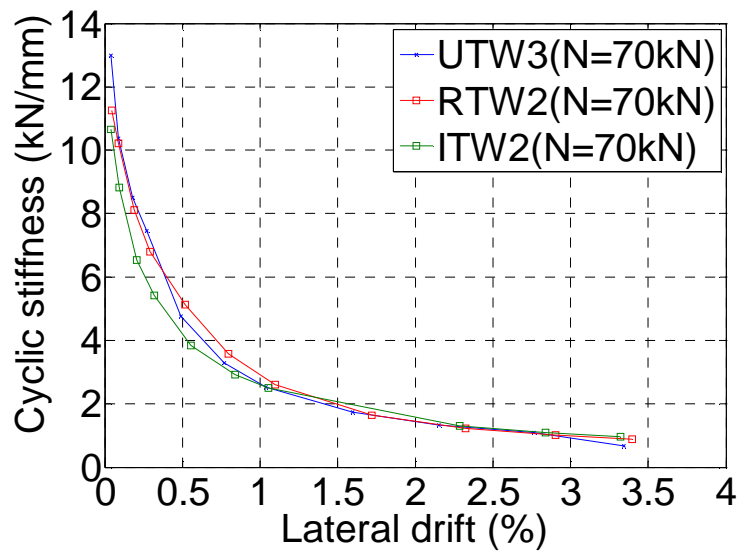

(b)

Figure 9 - Overall cyclic stiffness of the walls vs. lateral drift. 
Considering the change in the overall stiffness, two distinct characteristics can be discussed here. Firstly, it is seen that the stiffness decreases exponentially and eventually approaches a certain value of residual stiffness at the end of the test. The rate of the decrease appears to be almost the same but the value of the stiffness is different at the same lateral drift depending on the initial stiffness, i.e. the overall cyclic stiffness increases with the vertical load at the same lateral drift. For RTW, the overall stiffnesses are almost identical for RTW2 and RTW3, regardless of the vertical load levels. But the effect of the vertical load level can still be seen in this typology of wall as RTW1 has the lowest overall cyclic stiffness for every lateral drift level when compared to the other walls. To compare the amount of degradation among UTW, RTW and ITW, the highest degraded wall for each typology is selected within the lateral drift from $0.04 \%$ to $3.34 \%$. It is then found that UTW has the highest degradation $(95 \%)$ followed by RTW $(92 \%)$ and ITW $(91 \%)$, respectively. The reason for this high degradation in UTW is that UTW, by definition, has no reinforcement to enhance the strength of the wall as in the case of RTW and ITW. It is also observed that, even though there is a degradation of the overall stiffness, the strength still keeps increasing until it reaches its peak point.

Moreover, under the same levels of vertical load and lateral drift, RTW has higher overall cyclic stiffness than UTW but lower than ITW (see Figure 9b). Specifically, it appears that UTW has the fastest degradation and that RTW degrades more rapidly than ITW. This is attributed to the fact that the damage in ITW is distributed to the infill material, therefore slowing the rate of degradation. Considering that RTW and ITW dissipate the same amount of energy at a given lateral drift, it appears that FRP is effective in the presence of the infill only in increasing the initial stiffness and the capacity of the wall (Pilaon 2010).

These results are in accordance with the energy dissipation results where the stiffness decreases rapidly while the walls are dissipating a large amount of energy exponentially.

\subsection{Equivalent viscous damping ratio (EVDR)}

The equivalent viscous damping gives a measure of all the energy dissipated in the structure throughout the experiment. It is calculated as in Equation (1) below (Magenes and Calvi 1997):

$$
\zeta_{e q}=\frac{E_{d}}{2 \pi\left(E_{S}^{+}+E_{S}^{-}\right)}
$$

where $E_{d}=$ dissipated hysteretic energy, $E_{s}{ }^{+}$and $E_{s}^{-}=$strain energy of an equivalent viscous system calculated at the maximum displacement in each loop for the positive and negative direction respectively.

The values of the equivalent viscous damping ratio are shown in Fig. 10. For all walls, the EVDR increases from the beginning of the loading until the walls reach a lateral drift of about $0.5 \%$, which corresponds to the transition region from the elastic to the plastic state in their envelope curves. Even though the EVDR should be equal to zero in the elastic range, some energy dissipation, occurred through internal friction of the joints, and non-recoverable deformation, due to compression of grain, are present. Beyond this drift, the EVDR remains almost constant until the wall reaches the maximum lateral drift. However, the EVDR for UTW3 abruptly increases after the lateral drift of $2.2 \%$, which corresponds to the opening of a crack in the wall and to the point where the maximum load has been reached and the softening branch of the curve begins. By examining the hysteretic loops of the specimen, it is also observed that the shape is much wider at the middle portion, which increases the EVDR by increasing the dissipated energy. In addition, it is observed that EVDR varies between the ranges of 0.1 to 0.2 when in plastic range. For the others walls, the damages were lower and this can be seen by the fact that the EVDR is almost constant after the plastic range has been reached.

The EVDR increases with the vertical load. The trend is clearly seen in Figure 10b for RTW, from the elastic to plastic range. In the other wall typologies this trend is not so apparent.

The EDVR is also influenced by the wall typology (see Figure 11). For the same vertical load, the UTW specimens appear to have higher values of EVDR at every lateral drift whilst the difference between ITW and UTW specimens is not clear. 


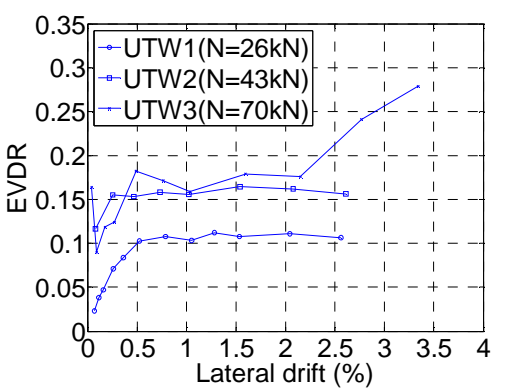

(a)

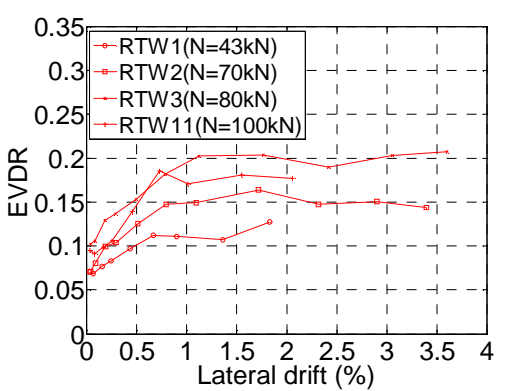

(b)

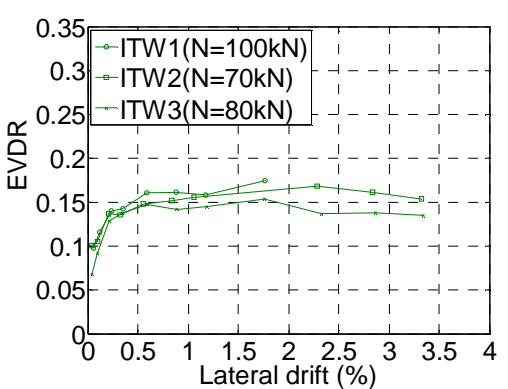

(c)

Figure 10 - Equivalent viscous damping for (a) UTW, (b) RTW and (c) ITW.

Pinched walls tend to have higher EVDR, depending on the severity of pinching. A severely pinched wall (RTW3) may have higher EVDR than a non-pinched wall (ITW3), provided that the dissipated energy is the same (see Figure 11c), since lesser strain energy is produced. While a mildly pinched wall (RTW2) may have lower EVDR than a non-pinched wall (ITW2) as shown in Figure 11b since more strain energy is produced. This indicates that not only pinching but also the vertical load affects the EVDR (Pilaon 2010).

When comparing the EVDR with other studies, it is found that the change of EVDR with lateral drift has the same pattern. The EVDRs obtained from the tests conducted by Heine (1997) and Toothman (2003) also increased until the yield point. Beyond this point, the EVDRs fluctuated about a certain mean value and remained almost constant until the end of the tests. At the inelastic lateral drift of about 2\%, Heine (1997) obtained EVDR values that ranged from 0.10-0.17 for light-frame shear walls with hold-downs under initial sequential phased displacement pattern (SPD), whereas the EVDRs reported by Toothman (2003) ranged from 0.15 to 0.20 . Therefore, it can be said that the range of values obtained for EVDR in this study $(0.11-0.18)$ is similar to the ones obtained in literature.

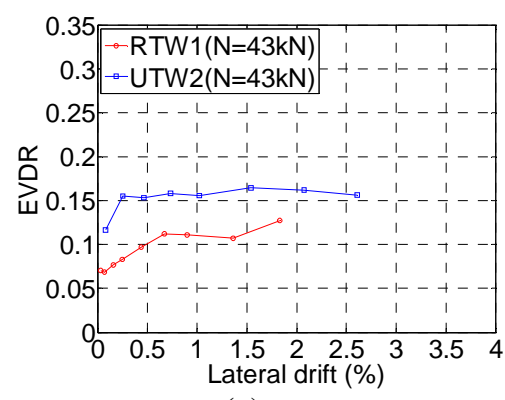

(a)

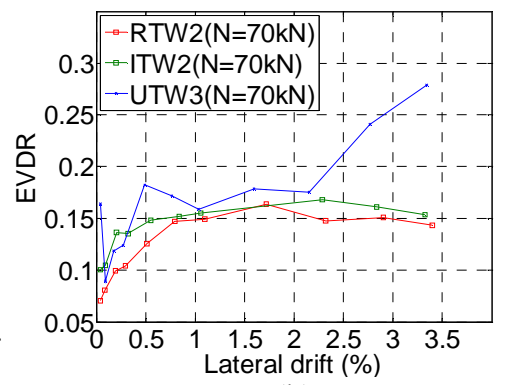

(b)

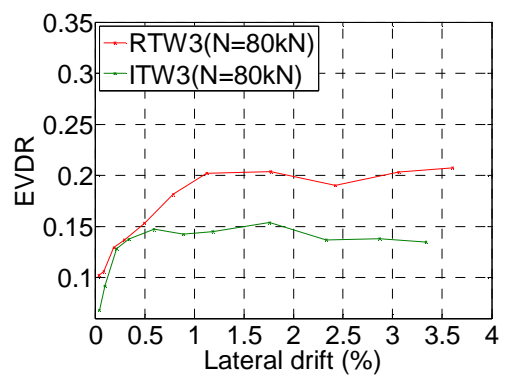

(c)

Figure 11 - Effect of wall typology at different vertical load levels: (a) $43 \mathrm{kN}$, (b) $70 \mathrm{kN}$ and (c) $80 \mathrm{kN}$.

\section{HYSTERETIC MODEL PROPOSED FOR TIMBER SHEAR WALLS}

Analyzing the existing hysteretic models and how they fit the experimental results obtained, the Takada 'Thin' model is selected as the basic model rule to simulate the cyclic behaviour of timber frame walls since it can sufficiently represent the experimental hysteretic loops of UTW3 and ITW1. Thus, in this study, hysteretic models have been proposed to fit the experimental data of UTW3 and ITW1 as these walls present a response governed by shear, as can be seen in Figure 12.

Analyzing the experimental results, the main characteristics observed were that the hysteretic loops display strength degradation at the same displacement demand and energy dissipation occurs also in the elastic range. Moreover the unloading stiffness is greater than the loading one, due to the fact that the energy is dissipated through internal friction and plastic deformation of timber joints that move and cannot recover their original position (Toothman 2003). 


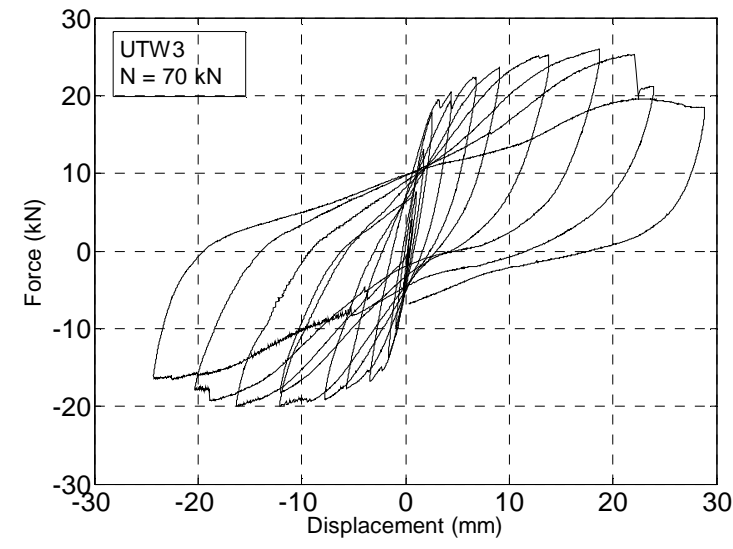

(a)

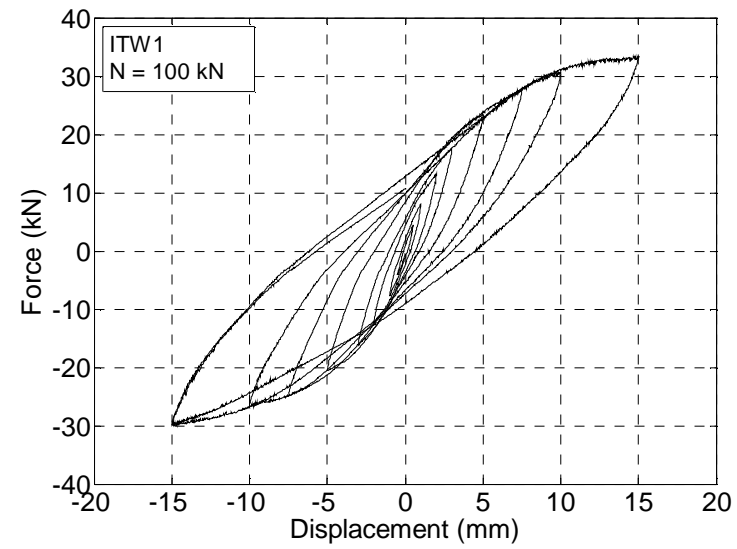

(b)

Figure 12 - Load-displacement curves for (a) UTW3 and (b) ITW1.

In UTW3, mild pinching occurs. The secant reloading and unloading stiffnesses degrade progressively as the excursion continues. The unloading continues until it reaches the point of force close to zero and the permanent displacement, $d_{p, i}$, where the crossing point is defined. After the crossing point, the reloading starts.

Taking into account the above features, a revision to the Takeda model is proposed. Figure 13 represents the modified Takeda hysteretic model without pinching effect used in this study (Takeda et al. 1970).

The envelope curve is obtained by the cyclic tests described above. Points in the elastic range should be on or below the line defined by the initial stiffness, $k_{e}$, to avoid negative dissipated energy resulted by using the energy-based method.

The loading path starts from the origin point $(0,0)$, aiming at the first given-force deformation (Line 1). Note that the first loading direction is on the negative side.

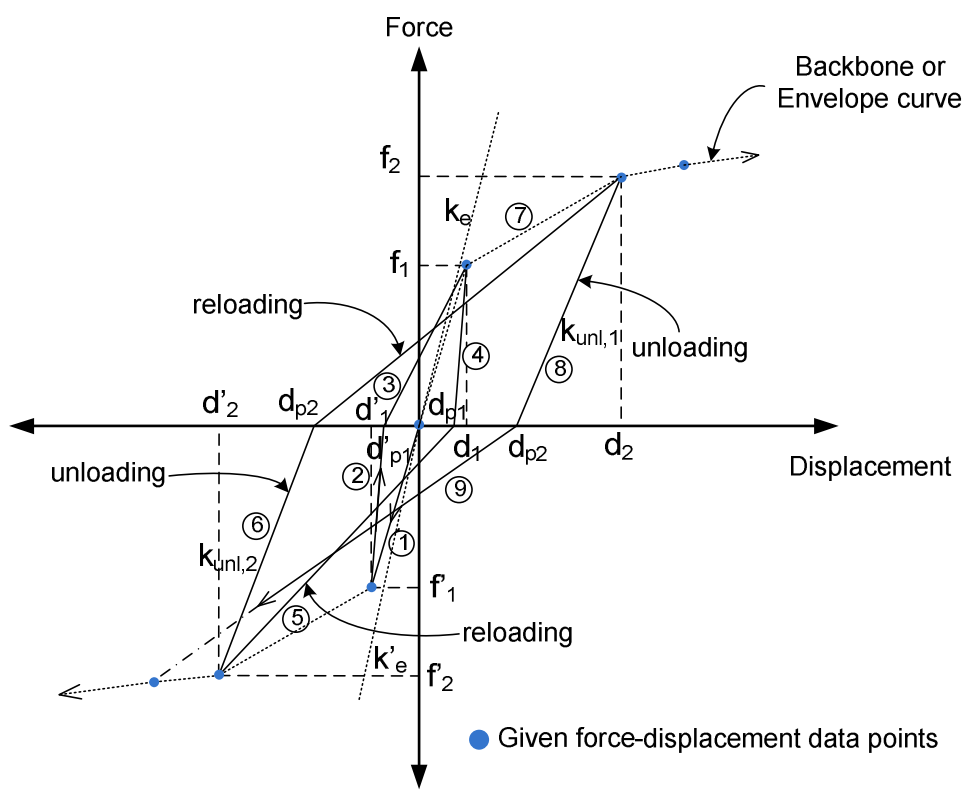

Figure 13 - Modified Takeda hysteretic model.

After the first point is reached $\left(d_{l}, f_{l}\right)$, the unloading starts and the unloading stiffness changes from $k_{e}$ to $k_{\text {unl, }}$ (for the first cycle), according to the Takeda and energy-based rules( Line 2). However, if the given point data produces a slope greater than $k_{e}$, i.e. above the elastic region, it is assumed that the unloading path from that point follows the same path to the origin. 
The unloading path continues until it meets the horizontal axis, defined as $d_{p l}^{\prime}$. After crossing the horizontal axis, the reloading starts, aiming at the next given force-displacement in the other direction (Line 3).

Then the unloading starts again, Line 4, along the unloading path which is defined by the updated unloading stiffness, $k_{u n l, 2}$, calculated using the unloading stiffness from the other direction. The Takeda and energy-based rules are applied at this point $\left(d^{\prime}{ }_{1}, f^{\prime}{ }_{1}\right)$. The unloading path continues until the displacement-intercept point is met, defined as $d_{p l}$. This completes one cycle.

As the reloading for the second cycle begins; it is directed to the next given force-displacement data in the direction of loading (Line 5). The other cycles are found in the same way, until the last given point, which is located in such a way that it aims at the previous maximum point in the loading direction.

The pinching effect was also considered. The base model considered was the one proposed by Ibarra et al. (2005). Briefly, the loading branches were divided in two, considering both the target displacement and the pinching force and the parameters modified in order to fit the model to the experimental results. For more information, see Pilaon (2010).

\subsection{Parameter estimation and comparison of results}

The mechanical parameters required to define the proposed hysteretic models had to be fitted to the experimental results obtained in the cyclic tests of the walls under analysis, as contemplated by the original models (Takeda et al. 1970, Ibarra et al. 2005, Priestley et al. 2007). An energy-based deterioration parameter was also found, which allowed incorporating strength and stiffness deterioration (Ibarra et al. 2005). Details of the calculations won't be reported here, as they can be found in the respective references.

By using the fitted parameters, the hysteretic force-displacement diagrams obtained from the updated models are compared to the experimental force-displacement diagrams. It is also intended to determine the cyclic stiffness deterioration by using the Takeda and the energy-based expressions. Both results are shown in Figure 14 for wall UTW3. The updated analytical models are able to simulate the experimental data well up to the input envelope displacement of less than the yield displacement as the difference of the permanent displacements is insignificant. When the input envelope displacement becomes higher than the yield point, the difference becomes significant.

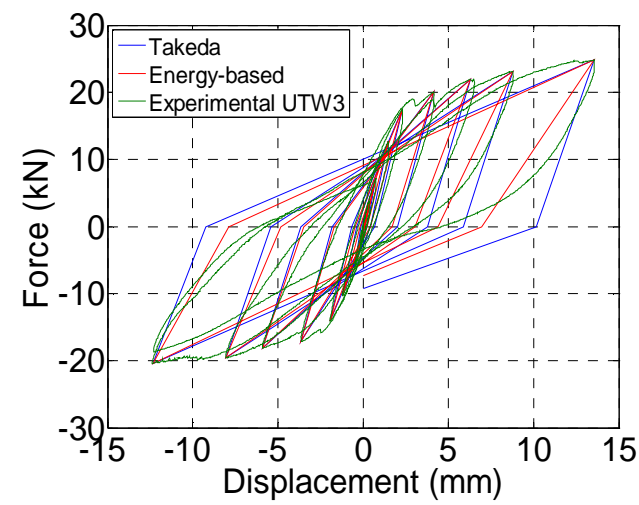

(a)

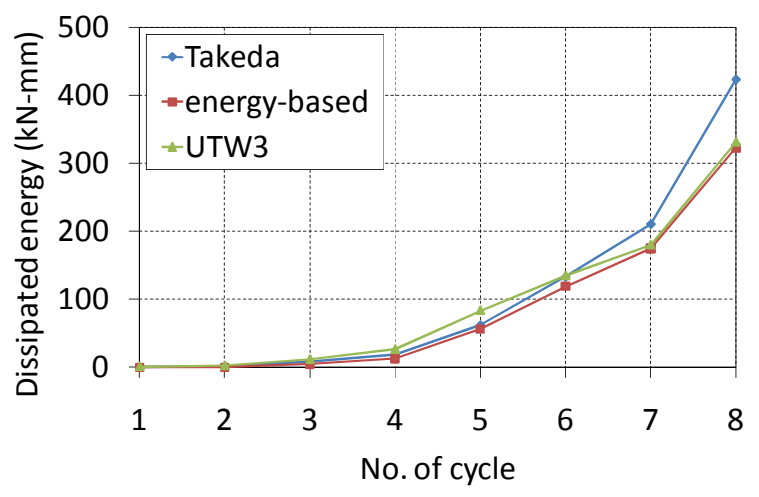

(b)

Figure 14 - (a) Hysteretic model of UTW3 without pinching and (b) cyclic dissipated energy.

For each cycle, the model with energy-based rule gives closer permanent displacements to the experimental ones. Moreover, considering the amount of cyclic energy dissipation (Figure 14a), it is observed that the model with the Takeda rule gives better results than the energy-based one up to the $6^{\text {th }}$ cycle, after which the model with energy-based rule gives almost similar energy dissipation. This occurs because the model is a static parameter one, so it is invariant with time or damage (Pang et al. 2007). Similar results were found also for the infill wall specimen ITW1, so it can be concluded that models with energy-based rules can give results which fit the experimental ones better than the Takeda model, since they are able to capture permanent displacements and energy dissipation at large displacements. 


\section{CONCLUSIONS}

This paper aims at studying the cyclic behaviour of traditional half-timbered walls typical of the Pombalino buildings. Three different wall typologies were considered. From the experimental campaign carried out it was possible to observe that for low values of vertical pre-compression, the walls show a flexural rocking mechanism, while for higher values a shear mechanism. The loaddisplacement curves do not have a clear yielding point. The shape of the hysteretic loops depends on the wall typology and the displacement level. Stiffness and strength degradation are higher for timber walls without infill, whilst the infill and strengthened walls are able to dissipate higher amounts of energy. Half-timbered walls present a greater ductility than modern timber shear walls. The cyclic stiffness increases with the vertical load. For the same levels of vertical load, strengthened walls exhibited higher overall cyclic stiffness than the timber frame walls. Moreover, the stiffness degradation was slower. The opposite happens when the strengthened walls are compared to the infill ones, pointing out the importance of the infill material in this type of walls. EVDR is affected both by pinching and by the vertical load level. For the same load level, EVDR is higher for the unreinforced walls. The modification to the hysteretic model here proposed was able to well represent the experimental results. However, caution should be assumed when considering different typologies and geometries.

\section{REFERENCES}

Czmoch, I., Thelandersson, S., and Larsen, H. (1991). "Effect of within member variability on bending strength of structural timber." Proceedings of the CIB-W18 Meeting 24, CIB, 25.

Kirkegaard, P., and Sørensen, J. (2008). A probabilistic approach for robustness evaluation of timber structures. DCE Technical Report, Aalborg University, 21.

Cóias e Silva, V. (2002). "Using advanced composites to retrofit Lisbon's old "seismic resistant" timber framed buildings." European Timber Buildings as an Expression of Technological and Technical Cultures, Éditions Elsevier.

Cóias, V. (2007). Reabilitação Estrutural de Edifícios Antigos. ARGUMENTUM, GECoPRA, Lisbon.

Dinehart, D. W., and Shenton III, H. W. (1998). "Comparison of static and dynamic response of timber shear walls." Journal of Structural Engineering, 124:6, 1104-1113.

Foliente, G. C. (1995). "Hysteresis modelling of wood joints and structural systems." Journal of Structural Engineering, 121:6, 1013-1022.

Folz, B., and Filiatrault, A. (2001). "Cyclic analysis of wood shear walls." Journal of Structural Engineering, 127:4, 433-441.

França, J. A. (1983). Lisboa Pombalina e o iluminismo. Bertrand, Lisbon.

Heine, C. P. (1997). Effect of Overturning Restraint on the Performance of Fully Sheathed and Perforated Timber Framed Shear Walls. MSc Thesis, Virginia Polytechnic Institute and State University.

Johnston, A. R., Dean, P. K:, and Shenton III, H. W. (2006). "Effects of vertical load and hold-down anchors on the cyclic response of wood framed shear walls." Journal of Structural Engineering, 132:9, 1426-1434.

Ibarra, L. F., Medina, R. A:, and Krawinkler, H. (2005). "Hysteresis Models that Incorporate Strength and Stiffness Degradation." Earthquake Engineering and Structural Dynamics, 34, 1489-1511.

Lam, F., Prion, H. G. L., and He, M. (1997). "Lateral resistance of wood shear walls with large sheathing panels." Journal of Structural Engineering, 123:14, 1666-1673.

Langenbach, R. (2007). "From "Opus Craticium" to the "Chicago Frame": Earthquake-resistant Traditional Construction." International Journal of Architectural Heritage, 1:1, $29-59$.

Langenbach, R. (2009). DON'T TEAR IT DOWN! Preserving the earthquake resistant vernacular architecture of Kashmir. UNESCO, New Delhi. 
Magenes, G., and Calvi, G. M: (1997). "In-Plane Seismic Response of Brick Masonry Walls." Earthquake Engineering and Structural Dynamics, 26, 1091-1112.

Mascarenhas, J. (2004). Sistemas de construção - V. Livros Horizonte, Lisbon.

Santos, S. (1997). Ensaios de Paredes Pombalinas. Nota Técnica No 15/97-NCE, LNEC, Lisbon.

Pang, W., Rosowsky, D., Pei, S., and van de Lindt, J. (2007). "Evolutionary Parameter Hysteretic Model for Wood Shear Walls." Journal of Structural Engineering, 133:8, 1118-1129.

Pilaon, P. (2010). Experimental cyclic behaviour of timber shear walls. MSc Thesis, Advanced Masters in Structural Analysis of Monuments and Historical Constructions.

Priestley, M. J. N., Calvi, G. M., Kowalsky, M. J. (2007). Displacement-Based Seismic Design of Structures. IUSS Press, Pavia.

Takeda, T., Sozen, M. A., and Nielsen, N. N. (1970). "Reinforced Concrete Response to Simulated Earthquake." Journal of the Structural Division, 96:12, 2557-2573.

Toothman, A. J. (2003). Monotonic and Cyclic Performance of Light-Frame Shear Walls with Various Sheathing Materials. MSc Thesis, Virginia Polytechnic Institute and State University.

Vasconcelos, G., and Lourenço, P. B. (2009). "In-Plane Experimental Behaviour of Stone Masonry Walls under Cyclic Loading." Journal of Structural Engineering, 135:10, 1269-1277. 